\title{
Aneurisma idiopático de artéria ilíaca comum direita em criança de três anos - relato de caso
}

\author{
Idiopathic right common iliac artery aneurysm in a three-year-old child - case report \\ Loraine Entringer Falqueto' (D), Gabriela Caetano Lopes Martins² (D), Arthur Akio Konno Saito² (D), \\ Ayrton Alves Aranha Junior² (D), Ziliane Caetano Lopes Martins² (iD
}

\begin{abstract}
Resumo
A incidência de aneurismas ilíacos em crianças não é conhecida, havendo apenas alguns relatos de casos na literatura sobre o tema. Neste estudo, é relatado o caso de um paciente masculino, 3 anos, com aneurisma sacular isolado na bifurcação da artéria ilíaca comum direita de origem idiopática, que foi submetido a ressecção, ligadura da artéria ilíaca interna e anastomose vascular término-terminal. Após 1 mês de seguimento, foi diagnosticada oclusão assintomática da anastomose. Devido à presença de circulação colateral, não houve repercussões clínicas da oclusão, e a criança apresentou evolução clínica favorável a médio prazo.
\end{abstract}

Palavras-chave: aneurisma congênito; aneurisma ilíaco; pediatria; criança.

\begin{abstract}
The incidence of iliac aneurysms in children is unknown and there are only a small number of case reports in the literature on the subject. This article describes the case of a 3-year-old male patient with an isolated saccular aneurysm at the bifurcation of the right common iliac artery, of idiopathic origin, which was repaired by resection, ligature of the internal iliac artery and end-to-end vascular anastomosis. After 1 month of follow-up, he was diagnosed with asymptomatic occlusion of the anastomosis. The occlusion had no clinical repercussions because of collateral circulation and the child has had a favorable clinical course over the medium term.
\end{abstract}

Keywords: congenital aneurysm; iliac aneurysm; pediatrics; child.

Como citar: Falqueto LE, Martins GCL, Saito AAK, Aranha Junior AA, Martins ZCL. Aneurisma idiopático de artéria ilíaca comum direita em criança de três anos - relato de caso. J Vasc Bras. 2021;20:e20200195. https://doi. org/10.1590/1677-5449.200195

${ }^{1}$ Hospital Pequeno Príncipe - HPP, Curitiba, PR, Brasil.

${ }^{2}$ Universidade Federal do Paraná - UFPR, Curitiba, PR, Brasil.

Fonte de financiamento: Nenhuma.

Conflito de interesse: Os autores declararam não haver conflitos de interesse que precisam ser informados.

Submetido em: Outubro 08, 2020. Aceito em: Janeiro 30, 2021.

O estudo foi realizado no Hospital Pequeno Príncipe (HPP), Curitiba, PR, Brasil. 


\section{INTRODUÇÃO}

A incidência de aneurismas ilíacos em crianças não é conhecida, havendo apenas alguns relatos de casos na literatura sobre o tema ${ }^{1}$. As etiologias mais frequentes de aneurismas arteriais incluem infecção, arterites, doenças do tecido conjuntivo, displasia fibromuscular e trauma, sendo os aneurismas idiopáticos os menos frequentes ${ }^{2}$.

Quando diagnosticados, os aneurismas de artéria ilíaca devem ser prontamente abordados devido ao alto risco de rotura, trombose ou embolização distal ${ }^{3}$. O tamanho reduzido das estruturas anatômicas na população pediátrica, o crescimento do paciente e a longa expectativa de vida tornam o tratamento desafiador ${ }^{4}$.

Este artigo aborda um paciente masculino de 3 anos de idade com aneurisma isolado de artéria ilíaca comum direita de origem idiopática. Serão detalhados a investigação clínica, o tratamento e a evolução do caso a médio prazo a fim de contribuir para os avanços no tratamento de aneurismas de grandes vasos em crianças.

\section{DESCRIÇÃO DO CASO}

Este relato foi aprovado pelo Comitê de Ética em Pesquisa (número do parecer 4.306.931), e os responsáveis pelo paciente consentiram com a sua realização. O paciente era do sexo masculino, pardo, 3 anos e 7 meses, $17 \mathrm{~kg}$, com antecedente de faringoamigdalite de repetição. Havia sido atendido em Pronto Atendimento com febre (temperatura axilar de $39,5^{\circ} \mathrm{C}$ ), mialgia, odinofagia, cefaleia, vômitos e diarreia há cerca de 9 dias. Ele não possuía histórico de cirurgias prévias, comorbidades ou alergias. Ao exame físico abdominal, foi palpada massa pulsátil com cerca de $6 \mathrm{~cm}$ em fossa ilíaca direita. Além disso, o paciente também não tinha antecedente familiar de doença aneurismática.

Foi realizada tomografia computadorizada (TC) de abdome e pelve com contraste, a qual evidenciou uma formação expansiva sacular na bifurcação da artéria ilíaca comum direita de 6,5 x 5,6 x 4,8 cm (Figura 1). Devido ao diagnóstico, o paciente foi encaminhado com urgência a um centro de referência pediátrico com cirurgia vascular.

Na admissão, o paciente encontrava-se estável hemodinamicamente, com membro inferior direito sem lesões cutâneas, sem edema e com força, trofismo e pulsos periféricos simétricos ao contralateral. Não foram registrados outros achados além da massa abdominal palpável pulsátil. Ele foi avaliado pela reumatologia, para investigar etiologias inflamatórias ou autoimunes, e pela infectologia, sob hipótese de aneurisma micótico. Não foi realizada investigação genética adicional pela ausência de história familiar e alterações fenotípicas suspeitas.

Entre os exames complementares realizados, o ecocardiograma transtorácico estava normal. A ultrassonografia (USG) de abdome demonstrou ausência do rim esquerdo e dilatação aneurismática da artéria ilíaca direita $(4,4 \times 4,2 \mathrm{~cm})$, com trombo mural associado e 3,1 cm de luz não trombosada. A TC de crânio estava normal. As culturas de urina, sangue e $s w a b$ orofaríngeo foram negativas. Foram solicitados exames laboratoriais gerais, que estavam normais, exceto pela velocidade de hemossedimentação (VHS) - $108 \mathrm{~mm} / \mathrm{h}$ - e pela proteína $\mathrm{C}$ reativa $(\mathrm{PCR})$ $29,4 \mathrm{mg} / \mathrm{L}$ - as quais estavam aumentadas. Com base nessas alterações, para investigação de vasculites, foram dosados imunoglobulinas (IgA e IgG aumentados e IgM normal: 572, 1.308 e $90 \mathrm{mg} / \mathrm{dL}$, respectivamente) e anticorpo anticitoplasmático de neutrófilo (ANCA), o qual foi negativo. As sorologias para hepatite $\mathrm{B}$ e $\mathrm{C}$,

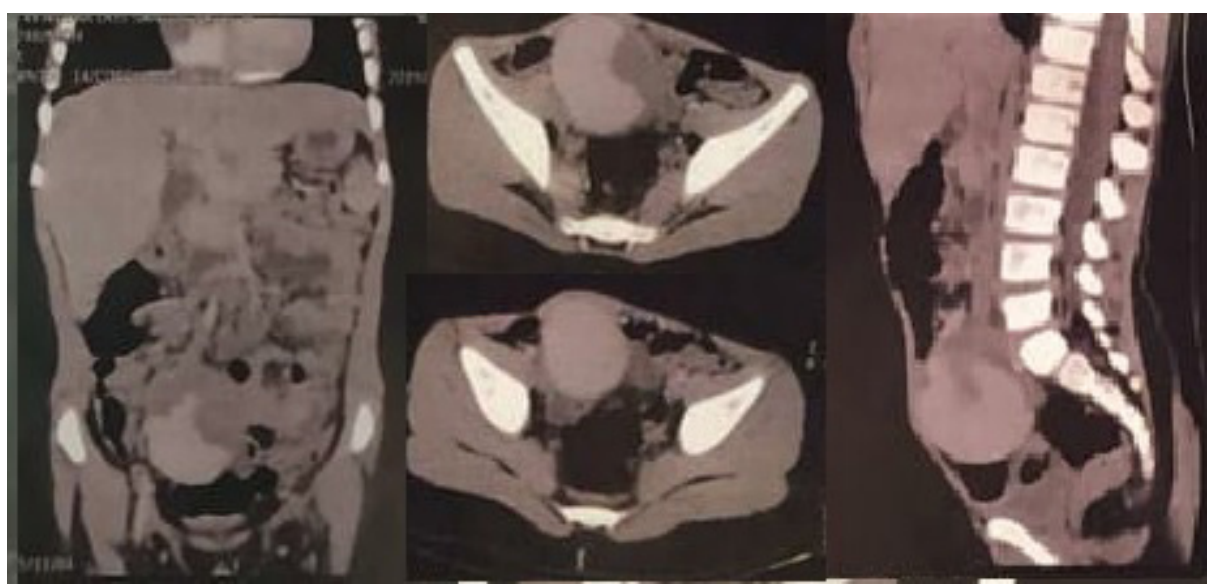

Figura 1. Imagens tomográficas com contraste do aneurisma de artéria ilíaca comum direita - coronal, axial e sagital. 
o teste tuberculínico com derivado proteico purificado (PPD) e o teste anti-HIV foram negativos.

Apesar do aumento de provas inflamatórias e das imunoglobulinas totais, não foi possível definir uma etiologia (autoimune ou infecciosa). Na tentativa de diminuir a resposta inflamatória sistêmica e melhorar os resultados cirúrgicos, a reumatologia pediátrica indicou teste terapêutico com metilprednisolona $(30 \mathrm{mg} / \mathrm{kg} / \mathrm{dia})$ por 5 dias. Previamente à pulsoterapia, foi realizada profilaxia com albendazol. Após o uso do corticoide, foram repetidos os exames, com a melhora do VHS $(32 \mathrm{~mm} / \mathrm{h})$ e do PCR $(<5 \mathrm{mg} / \mathrm{L})$. Dessa forma, para auxiliar no diagnóstico através de biópsia e cultura do aneurisma, bem como para evitar complicações como rotura, tromboembolia e dissecção, foi realizado o tratamento cirúrgico.

$\mathrm{O}$ acesso cirúrgico escolhido foi incisão em $\mathrm{J}$ na fossa ilíaca direita e dissecção do espaço extraperitoneal (incisão de Gibson). Após o reparo proximal da artéria ilíaca comum e distal da artéria ilíaca externa (Figura 2), foram realizadas abertura do aneurisma sacular e sutura hemostática do óstio da artéria ilíaca interna. Foi feita a remoção dos trombos e ressecção do segmento aneurismático; a reconstrução vascular foi uma anastomose términoterminal entre a artéria ilíaca comum e a artéria ilíaca externa, com pontos separados de polipropileno 6.0 (Figura 3) com auxílio de lupa cirúrgica com aumento 2,5 vezes. O procedimento transcorreu em 4 horas, sem intercorrências e sem necessidade de transfusão sanguínea. A análise anatomopatológica da parede do aneurisma e dos trombos foi de espessamento fibroso mural e intimal com ateroma focalmente calcificado, trombos recentes e em organização. A cultura foi negativa. $\mathrm{O}$ aneurisma foi classificado como congênito/idiopático.

O paciente foi mantido em observação em unidade de terapia intensiva por 48 horas. Durante os primeiros 6 dias de pós-operatório, ficou internado e recebeu enoxaparina $10 \mathrm{mg} / \mathrm{dia}$. No exame físico diário, constatouse membros inferiores simétricos, bem perfundidos e pulsos periféricos também simétricos. A USG com Doppler demonstrou perviedade da anastomose. Após a alta hospitalar, o paciente permaneceu em uso de ácido acetilsalicílico $50 \mathrm{mg}$ ao dia.

No seguimento ambulatorial, 1 mês após a cirurgia, o membro inferior direito estava sem edema, sem lesões cutâneas, mas com pulso periférico não palpável. Na USG com Doppler de controle, foi observada oclusão a nível da anastomose, porém com circulação colateral e sem repercussão clínica. Após 13 meses de seguimento com conduta expectante, não foi observada diferença de trofismo entre os membros.

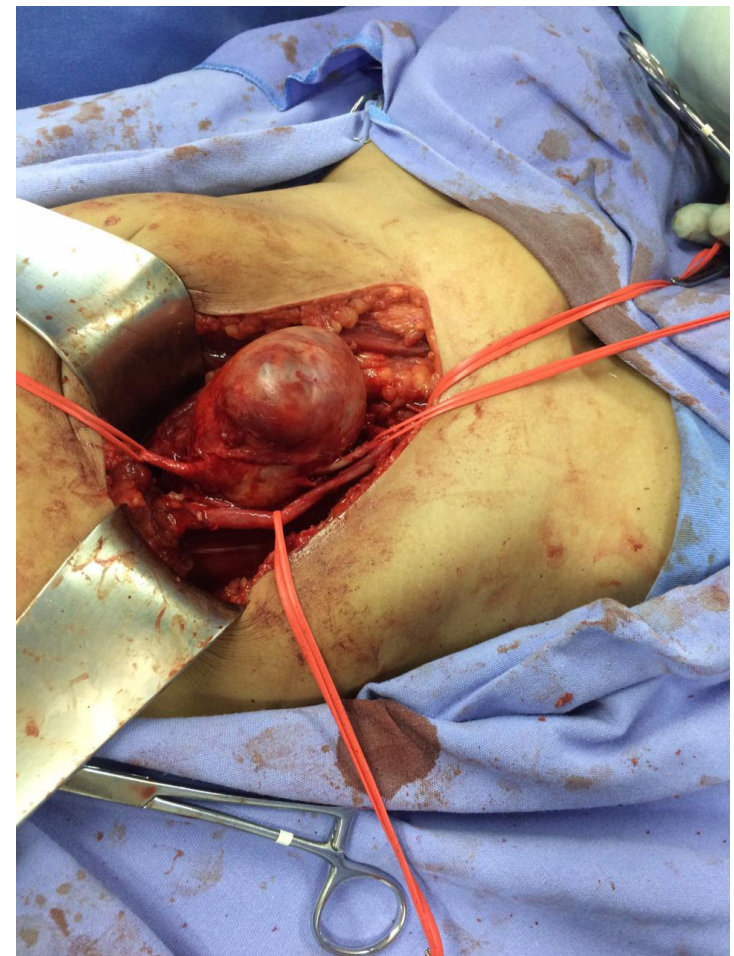

Figura 2. Foto intraoperatória do aneurisma idiopático de artéria ilíaca comum direita isolado, com controle proximal e distal.

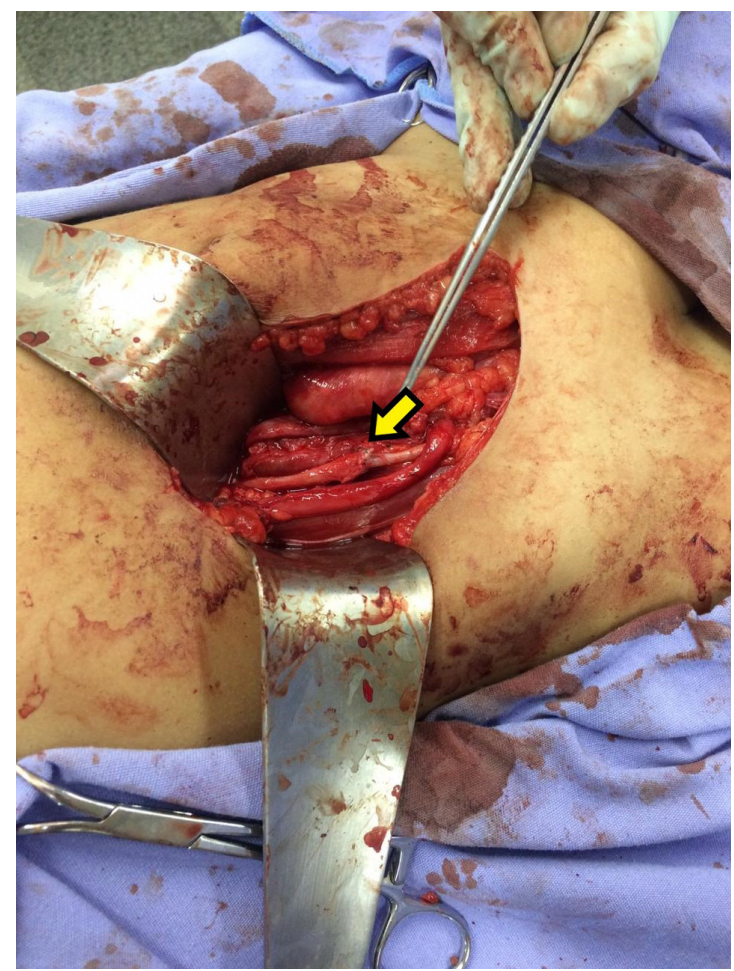

Figura 3. Foto intraoperatória mostrando o aspecto final da anastomose término-terminal das artérias ilíaca comum e ilíaca externa direita (seta) após a ressecção do aneurisma. 


\section{DISCUSSÃO}

Os aneurismas são patologias raras em pediatria, principalmente de vasos de grande calibre e isolados ${ }^{5}$. Sarkar et al. ${ }^{2}$ classificaram os aneurismas arteriais em crianças em nove tipos: I) causado por infecção arterial; II) aortoarterite de célula gigante; III) doença autoimune do tecido conjuntivo; IV) doença de Kawasaki; V) com degeneração da camada média (síndromes de Marfan e Ehlers-Danlos); VI) associados a outras formas não inflamatórias de degeneração da camada média; VII) associados a displasias vasculares; VIII) aneurismas congênitos/idiopáticos; IX) pseudoaneurismas devido a lesão vascular.

Os aneurismas congênitos/idiopáticos são incomuns e exigem uma investigação detalhada para exclusão de outras causas ${ }^{3}$. No caso relatado, o aneurisma foi assim classificado devido à ausência de achados clínicos, laboratoriais ou anatomopatológicos que indicassem outras etiologias, como infecção, trauma, malformação vascular ou doenças do tecido conjuntivo.

Com base na história pregressa de amigdalites de repetição, a principal hipótese era de aneurisma micótico. Todavia, não foi confirmado na biópsia, e o paciente não teve novas infecções após o tratamento adequado. A pesquisa de autoanticorpos auxilia no diagnóstico pré-operatório de vasculites autoimunes. No exame físico, a avaliação da estatura, da hipermobilidade articular, da pele e das características de face e membros são fundamentais para a busca de alterações genéticas e autoimunes, guiando a investigação. Os antecedentes patológicos, a história familiar e o exame físico completo são cruciais para o diagnóstico correto. O achado histológico de fibroplasia da íntima é uma alteração frequente nos aneurismas idiopáticos, sendo, provavelmente, uma lesão secundária ao processo e não um fator etiológico ${ }^{2}$.

O tratamento cirúrgico é a indicação padrão por causa da evolução natural com rotura, trombose e tromboembolia ${ }^{2,3}$. Foram relatados na literatura o uso de enxertos (próteses, veias crio preservadas e enxertos autólogos), embolização, plicatura e ressecção com anastomose primária ${ }^{1,3,6-9}$. Essa última foi a abordagem de eleição. Recomenda-se utilizar pontos simples em toda a circunferência da anastomose, uma vez que a sutura contínua pode ser um fator de risco para estenose ao longo do crescimento da criança ${ }^{6,10}$. Há ainda a abordagem endovascular, a qual vem surgindo como uma alternativa promissora nas correções vasculares pediátricas ${ }^{11}$.

Os pacientes com aneurismas idiopáticos devem ser acompanhados devido ao risco de recidiva, novos aneurismas ou complicações da correção. A USG com Doppler é o exame de imagem de escolha ${ }^{10}$. Davis et al. ${ }^{12}$ recomendam o seguimento anual. Outra recomendação é uso de antiagregante plaquetário por 6 meses após a intervenção.

Neste paciente, foi mantida a antiagregação plaquetária e foi identificada oclusão ao nível da anastomose após 1 mês de seguimento, sem repercussões clínicas. Foi optada pela conduta expectante e não houve discrepâncias de trofismo entre os membros até a consulta mais recente, após 13 meses de seguimento. Todavia, é necessário seguimento a longo prazo para exclusão de sequelas relacionadas ao desenvolvimento da criança e do membro.

Conclui-se que o manejo de aneurismas de artéria ilíaca em crianças é um desafio tanto pela raridade dos casos quanto pelas limitações anatômicas (dimensões) e pelo crescimento da criança. A conduta cirúrgica é a de escolha, mas não há consenso sobre o momento exato de indicação e quanto à técnica cirúrgica preferencial. No caso relatado, optou-se pela ressecção e anastomose primária. Apesar da oclusão da anastomose após 1 mês, obteve-se sucesso no tratamento do aneurisma. Até o momento, não foram observadas sequelas que afetaram o desenvolvimento do paciente, sendo fundamental o seguimento a longo prazo.

\section{AGRADECIMENTOS}

Agradecimentos especiais devem ser dados aos médicos de outras especialidades responsáveis pelo atendimento do paciente do caso relatado. Ao Doutor Renato Pedro de Almeida Torres, Cardiologista Pediátrico, e à Doutora Márcia Bandeira, Reumatologista Pediátrica, nosso muito obrigado.

\section{REFERÊNCIAS}

1. Lee JH, Oh C, Youn JK, Han JW, Kim HY, Jung SE. Right iliac arterial aneurysm in a 4-year-old girl who does not have a right external iliac artery. Ann Surg Treat Res. 2016;91(5):265-8. http://dx.doi. org/10.4174/astr.2016.91.5.265. PMid:27847800.

2. Sarkar R, Coran AG, Cilley RE, Lindenauer SM, Stanley JC. Arterial aneurysms in children: clinicopathologic classification. J Vasc Surg. 1991;13(1):47-56. http://dx.doi.org/10.1016/0741-5214(91)90011-I. PMid:1987396.

3. Zaidan LR, Siddique MT, Sharif MA, AIGarni S, Alomran F, Koussayer $S$. Isolated idiopathic right common iliac artery aneurysm presenting as acute appendicitis in a 9-year-old girl: a case report and literature review. Ann Vasc Surg. 2019;61:469.e13-9. http:// dx.doi.org/10.1016/j.avsg.2019.05.026. PMid:31382004.

4. Hoshiko FM, Zampieri EHS, Dalio MB, Dezotti NRA, Joviliano EE. Reparo de aneurisma de artéria ilíaca roto em criança. J Vasc Bras. 2017;16(1):48-51. http://dx.doi.org/10.1590/1677-5449.008616. PMid:29930623.

5. Brunkwall J, Hauksson $\mathrm{H}$, Bengtsson $\mathrm{H}$, Bergqvist D, Takolander R, Bergentz SE. Solitary aneurysms of the iliac arterial system: an estimate of their frequency of occurrence. J Vasc Surg. 1989;10(4):381-4. http://dx.doi.org/10.1016/0741-5214(89)90411-4. PMid:2795762.

6. Zimmermann A, Kuehnl A, Seidl S, Eckstein $\mathrm{HH}$. Idiopathic aneurysm of the common iliac artery in an 11-year-old child. J Vasc 
Surg. 2009;50(3):663-6. http://dx.doi.org/10.1016/j.jvs.2009.04.056. PMid:19576718.

7. Krysiak R, Żyłkowski J, Jaworski M, Brzewski M, Bober-Olesińska K Neonatal idiopathic aneurysm of the common iliac artery. J Vasc Surg Cases Innov Tech. 2019;5(2):75-7. http://dx.doi.org/10.1016/j. jvscit.2018.10.002. PMid:31025026.

8. Moritz MW. Primary iliac artery aneurysm in a two-year-old girl. Ann Vasc Surg. 1986;1(3):392-5. http://dx.doi.org/10.1016/S08905096(06)60143-X. PMid:3504354.

9. Taketani S, Imagawa H, Kadoba K, Sawa Y, Sirakura R, Matsuda H. Idiopathic iliac arterial aneurysms in a child. J Pediatr Surg. 1997;32:1519. http://dx.doi.org/10.1016/S0022-3468(97)90582-0.

10. Chithra R, Ajai Sundar R, Velladuraichi B, Sritharan N, Amalorpavanathan J, Vidyasagaran T. Pediatric isolated bilateral iliac aneurysm. J Vasc Surg. 2013;58(1):215-6. http://dx.doi.org/10.1016/j.jvs.2012.11.036. PMid:23433815.

11. Başpınar O, Vuruşkan E, Coşkun S, Aldudak B. Transcatheter treatment of a symptomatic giant iliac artery aneurysm with a begraft peripheral stent in a 2-year-old child. Pediatr Cardiol. 2020;41(5):1067-70. http://dx.doi.org/10.1007/s00246-019-02266-1. PMid:31848637.

12. Davis FM, Eliason JL, Ganesh SK, Blatt NB, Stanley JC, Coleman DM. Pediatric nonaortic arterial aneurysms. J Vasc Surg. 2016;63(2):46676.e1. http://dx.doi.org/10.1016/j.jvs.2015.08.099. PMid:26804218.
Correspondência Loraine Entringer Falqueto Rua Desembargador Motta, 1070, $6^{\circ}$ andar, Sala da COREME CEP 80250-060 - Curitiba (PR), Brasil

Tel.: (11) 99860-6409 E-mail: lorainevni@gmail.com

Informações sobre os autores

LEF - Residente de Cirurgia Pediátrica, Hospital Pequeno Príncipe

(HPP).

GCLM and AAKS - Acadêmicos de Medicina, Universidade Federal do Paraná (UFPR).

AAAJ - Doutor em Clínica Cirúrgica,a Universidade Federal do Paraná (UFPR).

ZCLM - Médica, Universidade Federal do Paraná (UFPR).

Contribuições dos autores Concepção e desenho do estudo: LEF, GCLM, ZCLM Análise e interpretação dos dados: LEF, GCLM, AAKS Coleta dos dados: LEF, ZCLM Redação do artigo: LEF, GCLM, AAKS Revisão crítica do texto: LEF, ZCLM Aprovação final do artigo*: LEF, GCLM, AAKS, AAAJ, ZCLM Análise estatística: N/A. Responsabilidade geral pelo estudo: ZCLM

*Todos os autores leram e aprovaram a versão final submetida ao J Vasc Bras. 